BRE 11122

\title{
Cell Proliferation after Ischemic Infarction in Gerbil Brain
}

\author{
MONICA DU BOIS, PHILLIP D. BOWMAN and GARY W. GOLDSTEIN \\ Departments of Pediatrics and Neurology, University of Michigan, Ann Arbor, MI 48109 (U.S.A.)
}

(Accepted January 28th, 1985)

Key words: gerbil — infarction - ischemia - $\left[{ }^{3} \mathrm{H}\right]$ thymidine incorporation - macrophage

\begin{abstract}
In order to study cell proliferation after ischemic infarction, a model of bilateral common carotid artery occlusion in the gerbil was developed. A comparison of survival rates after $15,30,45$ and $60 \mathrm{~min}$ of occlusion revealed that 45 min was the maximum duration of ischemia after which most $(72 \%)$ of the gerbils were alive at 1 week. The administration of pentobarbital (single dose, $30 \mathrm{mg} / \mathrm{kg}$ ) postoperatively to badly seizing animals increased survival to $100 \%$. Large, well-demarcated infarcts were present in posterior thalamus or midbrain in $62 \%$ of gerbils subjected to $45 \mathrm{~min}$ bilateral occlusion. In $60 \%$ of these animals the infarcts were unilateral; in $40 \%$ they were bilateral. To quantitate cell proliferation in the infarcts from $12 \mathrm{~h}$ to 25 days after ischemia, gerbils were injected with [ $\left.{ }^{3} \mathrm{H}\right]$ thymidine $4 \mathrm{~h}$ prior to sacrifice, and autoradiographs were prepared from sectioned brains. Proliferation took place from 2 to 7 days after occlusion, with a maximum of $24 \%$ labeled cells at 6 days.
\end{abstract}

\section{INTRODUCTION}

Cells in the central nervous system of the adult normally have a very low turnover rate. However, proliferation of glia and microvessel cells is stimulated in response to certain types of injury, and this may be analogous to wound healing processes in other tissues. Hypertrophy and proliferation of astrocytes in central nervous system lesions have long been recognized, and increased numbers of astrocytes have been demonstrated quantitatively in experimentally-induced stab wounds $s^{6.24}$ and kainic acid-induced lesions ${ }^{31}$. Phagocytic cells of both microglial and hematogenous origin and microvessel endothelial cells have also been shown to proliferate in various mechanical injuries of brain and spinal cord1.5.6.33.

Cellular proliferation also occurs following ischemic infarction. Information about the responses of glia, macrophages and capillaries as a function of time after infarction has come primarily from autopsy material, and there is little quantitative data to demonstrate the reproductive capacities of these cell types in damaged brain tissue. The paucity of quantitative data has been due in part to a lack of an animal model in which infarction is produced with predictability and with a high survival rate, and in which proliferative responses can be systematically monitored.

The Mongolian gerbil is widely used for studying biochemical $7,22,29,40$, behavioral ${ }^{19,20}$ and morphological ${ }^{9,17.18 .21 .39}$ effects of cerebral ischemia. Because of negligible communication between the vertebrobasilar and carotid arterial supplies in this animal, cerebral ischemia can be experimentally produced by occluding one or both common carotid arteries. Of late, bilateral models, in which both carotids are transiently occluded and reperfusion is allowed to proceed for a length of time appropriate for the particular investigation, appear to be gaining favor over unilateral models. This is most likely due to the high percentage of deaths (40-60\%) which occur within $24 \mathrm{~h}$ after permanent, unilateral ligation, and the low incidence of cerebral ischemia in the surviving animals ${ }^{20}$.

In the present study, a model of bilateral ischemia in the gerbil is described which produces a high incidence of non-lethal infarction in the posterior thalamus/midbrain region. Tritiated thymidine autoradiography and histological evaluation were utilized to investigate the proliferative responses which occur as a function of time after ischemic infarction.

\footnotetext{
Correspondence: Monica du Bois, Pediatric Neurology, R6060 Kresge II, University of Michigan, Ann Arbor. MI 48109, U.S.A.
} 


\section{MATERIALS AND METHODS}

\section{Carotid artery occlusion}

Adult Mongolian gerbils (Meriones unguiculatus) of both sexes were purchased from Tumblebrook Farm. Females weighed $50-60 \mathrm{~g}$ when used; males were $60-75 \mathrm{~g}$. The animals were anesthetized by i.p. injection of $70 \mathrm{mg} / \mathrm{kg}$ sodium pentobarbital, the fur in the ventral neck region clipped and the skin wetted with $70 \%$ ethanol. Under a dissecting microscope, a small midline incision was made, and each common carotid artery was carefully dissected from associated nerves and connective tissue. A 3 in. length of 4-0 suture was looped around each artery, and while gently lifting the two ends of the suture, a Mayfield microaneurysm clip was applied. Complete cessation of blood flow in the carotids was verified visually. A sterile piece of gauze wetted with saline was used to cover the wound during the occlusion period. Shamoperated gerbils were subjected to identical procedure with the exception of applying the Mayfield clips.

After the occlusion period, the clips were removed from the carotids, the skin wound sutured with 6-0 silk and the animals placed in clean, warm cages for recovery. During the next several hours the gerbils were observed for signs of neurological damage, i.e. seizures, circling, trembling, etc. Some of the gerbils were given an additional injection of pentobarbital $(30 \mathrm{mg} / \mathrm{kg})$ after recovery from the surgery, as described in Results. Animals had free access to food and water at all times.

\section{Histology and autoradiography}

At selected times after the carotid occlusions, gerbils were injected intraperitoneally with $2 \mu \mathrm{Ci} / g$ body weight of $\left[{ }^{3} \mathrm{H}\right]$ thymidine (New England Nuclear). To avoid diurnal variations in $\left[{ }^{3} \mathrm{H}\right]$ thymidine incorporation, injections were always given between 10.00 and $12.00 \mathrm{~h}$. After $4 \mathrm{~h}$, they were anesthetized with pentobarbital $(70 \mathrm{mg} / \mathrm{kg})$ and given sodium heparin (100 units, i.p.), and perfused via the left ventricle and aorta with phosphate buffered saline (PBS) followed by formalin (10\% in PBS). Brains were removed and left in fixative for an additional 2-4 days, embedded in paraffin and sectioned at $6 \mu \mathrm{m}$. Every fiftieth section, or one section every $300 \mu \mathrm{m}$, was mounted onto microscope slides. For autoradiography, sections were coated with warmed Kodak NTB2 emulsion, stored at $4{ }^{\circ} \mathrm{C}$ for approximately 12 days, then developed Sections were then stained with hematoxylin and eosin. In order to stain myelin, some sections were stained with luxol fast blue/periodic acid-Schiff, and this was carried out prior to autoradiography to prevent damage to the emulsion by the heat involved in the staining procedure. The prestaining had no effect on the autoradiographic labeling, and comparison of autoradiographs prepared from adjacent sections stained by each of the two methods revealed identical results. Sections through the approximate center of each infarct were selected, and the percentage of $\left[{ }^{3} \mathrm{H}\right]$ thymidine labeled cells in each infarct was calculated by counting all labeled and unlabeled nuclei $(500-1000$ cells $)$ within the $500 \times$ field across the diameter of the infarct.

\section{RESULTS}

\section{Survival after ischemia}

In order to determine a duration of occlusion which would cause considerable neurological damage and yet allow survival of the animal for several days, 30 gerbils were subjected to $0-60 \mathrm{~min}$ of bilat'eral common carotid artery occlusion. The percentages of animals alive at $24 \mathrm{~h}$ and 7 days after the ischemic episode were compared (Fig. 1).

Death of non-surviving gerbils always occurred during or shortly after violent seizure activity. To test whether pentobarbital might alleviate the seizure activity and prolong the life of these animals, 30 animals were subjected to $30-60 \mathrm{~min}$ of occlusion. Half of the gerbils that exhibited severe seizure activity upon recovery from the anesthetic were given an additional dose, $30 \mathrm{mg} / \mathrm{kg}$, of pentobarbital. None of

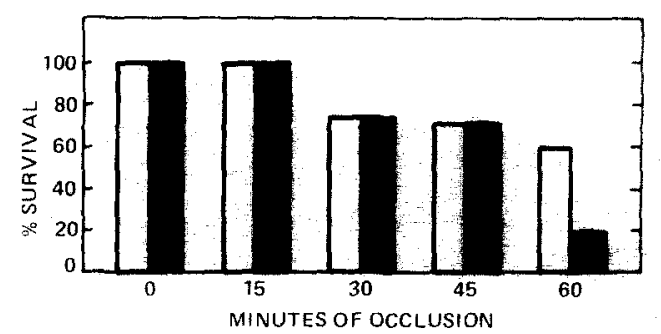

Fig. 1. Survival of gerbils at $24 \mathrm{~h}$ (open bars) and 7 days (closed bars) after various durations of bilateral occlusion of the common carotid arteries. Five to 8 gerbils per duration were used $(0$ min gerbils were sham operated.) 
the animals receiving this drug treatment had further seizure activity, and all were alive $24 \mathrm{~h}$ later (Table I). In contrast, all of the gerbils that had exhibited severe seizure activity and that had not received pentobarbital treatment continued to have seizures and died within $24 \mathrm{~h}$. Therefore, during the remainder of the study, all animals having severe seizure activity upon recovery from the surgery were given an additional, single dose of pentobarbital $(30 \mathrm{mg} / \mathrm{kg}$ ).

For quantifying cell proliferation after infarction, gerbils were subjected to $45 \mathrm{~min}$ bilateral occlusion of the common carotid arteries. This occlusion duration was used because, while it produced a severe insult, animals survived at least a week after the occlusion (Fig. 1). Forty-seven gerbils were sacrificed between $12 \mathrm{~h}$ and 25 days after the ischemic insult.

Postocclusion behavior was not a completely reliable means of predicting whether or not a particular gerbil had an infarct, although some trends were apparent (Table II). All gerbils that had severe seizures, and most of those that had mild seizures, developed infarcts. However, neurologic deficit was not observed in all of the gerbils that developed infarcts. Conversely, some of the animals that had exhibited head jerking, tremors or circling behavior did not have infarcts. No sex differences were observed with regard to the incidence of infarction.

\section{Proliferation}

Brains from forty-seven gerbils that had undergone 45 min occlusion of the common carotid arteries and 3 sham-operated gerbils were sectioned and evaluated histologically. Well-defined areas of necrosis (infarcts) occurred in $62 \%$ of the occluded gerbils. These were always located in the area of the pos-

\section{TABLE I}

Effect of pentobarbital treatment on survival of gerbils having severe seizures on recovery from $30-60 \mathrm{~min}$ bilateral occlusion of the common carotid arteries

All gerbils in the study were anesthetized with pentobarbital, $70 \mathrm{mg} / \mathrm{kg}$. Pentobarbital-treated gerbils were given an additional, single dose of pentobarbital, $30 \mathrm{mg} / \mathrm{kg}$, after seizure activity had begun.

\begin{tabular}{lllc} 
& $\begin{array}{l}\text { Alive } \\
\text { at } 24 h\end{array}$ & $\begin{array}{l}\text { Dead } \\
\text { by } 24 h\end{array}$ & $\begin{array}{l}\% \\
\text { Survival }\end{array}$ \\
\hline Control & 0 & 6 & 0 \\
Pentobarbital-treated & 7 & 0 & 100 \\
\hline
\end{tabular}

\section{TABLE II}

Behavior of gerbils and incidence of infarction after $45 \mathrm{~min}$ occlusion of the common carotid arteries

Behavior was observed for 2-4 h after recovery from pentobarbital anesthesia. Gerbils were sacrificed between $12 \mathrm{~h}$ and 25 days after the occlusion. All brains were sectioned and evaluated histologically

\begin{tabular}{lcc}
\hline Behavior & No. (\%) & $\begin{array}{l}\text { No. with } \\
\text { infarct }(\%)\end{array}$ \\
\hline $\begin{array}{l}\text { Normal } \\
\text { Mild seizures, trembling }\end{array} \quad 30(64)$ & $17(57)$ \\
$\quad$ or circling & $8(17)$ & $3(37)$ \\
Severe seizures & $9(19)$ & $9(100)$ \\
Total & $47(100)$ & $29(62)$ \\
\hline
\end{tabular}

terior thalamic nuclei or midbrain reticular formation. In $60 \%$ of the cases the infarcts were present in only one side of the brain, while $40 \%$ were present bilaterally, these being roughly symmetrical in size and location. No difference in the size of infarcts was noted between pentobarbital treated and untreated animals.

In order to quantitate cellular proliferative responses at different times after ischemia, gerbils were injected with $\left[{ }^{3} \mathrm{H}\right]$ thymidine before sacrifice, and autoradiographs were prepared from the sectioned brains. Fig. 2 is an autoradiograph of a thalamic infarct 6 days after occlusion. Cells with nucle-1 ar incorporation of $\left[{ }^{3} \mathrm{H}\right]$ thymidine, which labels them as having been in the DNA synthetic phase of the cell cycle at the time the isotope was given to the animal, were present in large numbers in the necrotic center of the infarct and in the surrounding, less damaged border zone. Labeled cells were observed in infarcts from 2 to 7 days after the ischemic insult (Fig. 3). Maximum proliferation, during which approximately $20 \%$ of the cells were labeled, occurred at 3-6 days postocclusion. The percentage of labeled cells in comparable brain regions from sham-operated control animals was less than $0.3 \%$. No labeling above control values was observed before 2 days or after 7 days postischemia. Labeling indices of pentobarbitaltreated animals were neither consistently higher nor lower than those of untreated animals at the same time point.

The histology of the infarcted area followed a consistent sequence of morphological changes according 


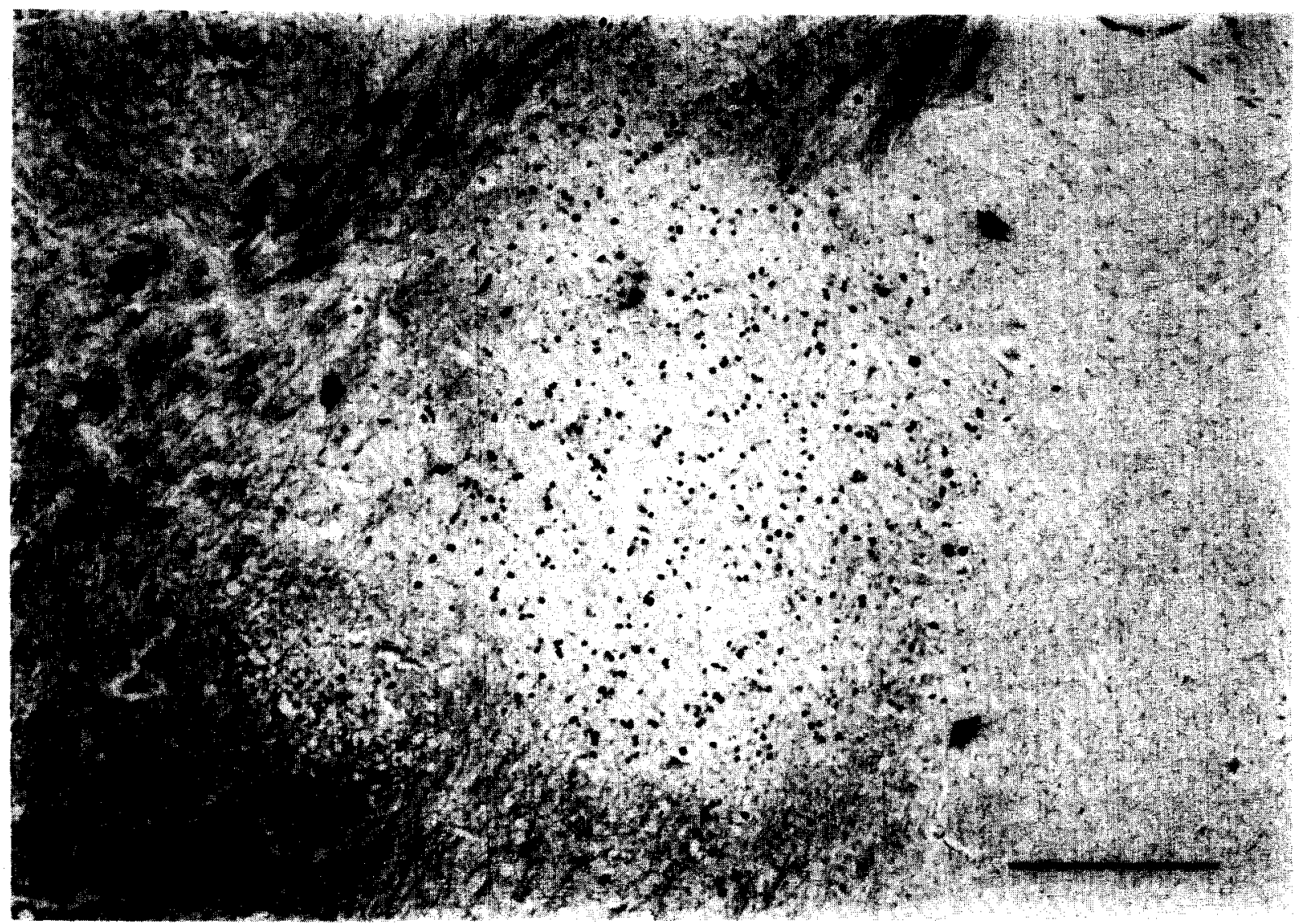

Fig. 2. Low magnification autoradiograph of a section through a posterior thalamic infarct, 6 days postocclusion. Intense labeling is present in the infarcted area (arrows). Luxol fast blue $/ \mathrm{P}$. A.S. hematoxylin. Bar $=500 \mu \mathrm{m}$.

to the duration of time since the ischemic episode. At 1-3 days postischemia, the area could be identified by the presence of pyknotic neurons, with well-demarcated borders between normal and infarcted tissue. By 3 days, monocytes were scattered throughout the damaged area. Labeled cells were first observed at 2 days and increased in number by 3 days (Fig. 4). The autoradiographic silver grains sometimes

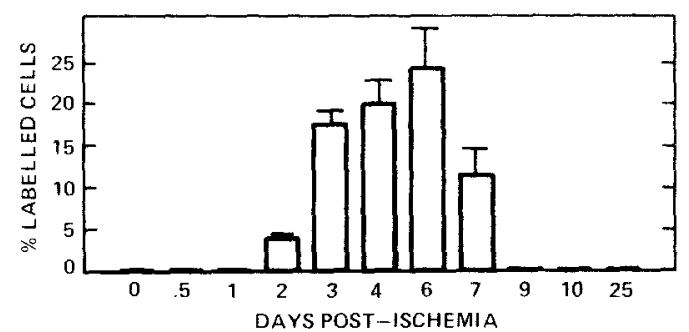

Fig. 3. The percentage of labeled cells in the infarcts as a function of time after 45 min occlusion. Data represents the mean of two, or the mean \pm S.E.M. of 3 , infarcted gerbils per time point. obscured the nucleus, and the identification of every labeled cell was not possible

The fourth day postischemia marked the appearance of numerous phagocytic cells (macrophages), identified by their large, 'foamy' cytoplasm, and from 5 to 8 days the infarct consisted of a denselypacked mass of these cells. At 6-7 days postocclusion, many macrophages and microvessel endothelial cells were labeled. Macrophages were present in smaller numbers after 7 days.

\section{DISCUSSION}

Although the majority of human strokes are due to ischemic infarction ${ }^{34.36}$, relatively little is known about the proliferative responses of brain cells as a function of time after ischemia. In the present study, an animal model is described in which cerebral infarction develops in the majority of the animals, occurring in a consistent, limited area of the brain. An 
occlusion period of $45 \mathrm{~min}$ was used in order to optimize the number of animals which developed infarcts but which survived for several days after the ischemic insult, and the percentage of survivors could be further increased by administering pentobarbital after occlusion to badly seizing gerbils. Marked cellular proliferation in the damaged area occurred from 2 to 7 days after ischemia.

Several components of the histopathological evolution of cerebral ischemic infarction, including neuronal death, disruption of the blood-brain barrier, gliosis and macrophage infiltration, have been described before ${ }^{10,17,18,27}$. However, in none of these studies was proliferation measured with $\left[{ }^{3} \mathrm{H}\right]$ thymidine autoradiography, or as a function of time after the ischemic insult. The sequence of post-infarction reactions described here, moreover, appears to closely mimic that which has been reported to occur in the human brain following stroke, particularly lesions resulting from arterial occlusion. Based on ex- amination of autopsy material, these are characterized early on by focal loss of nerve cells and disruption of myelin followed by hypertrophy and hyperplasia of astrocytes in the area beginning at approximately 3 days. Macrophages accumulate between 2 and 5 days and may persist for several weeks ${ }^{37}$. The demonstration in the present gerbil model of maximum cell proliferation at $3-6$ days postischemia is consistent with the astrocyte hyperplasia and macrophage accumulation reported for human infarcts, although in larger lesions the astrocyte reaction and macrophage phagocytic activity may persist for a longer time. Further studies are now underway, using immunocytochemical techniques in order to more accurately identify the various cell types, to describe in detail the pathology of infarction in this model.

Barbiturates have been frequently reported to have a protective effect on the brain during ischemia15,26,38, perhaps by inhibiting the ischemia-in-

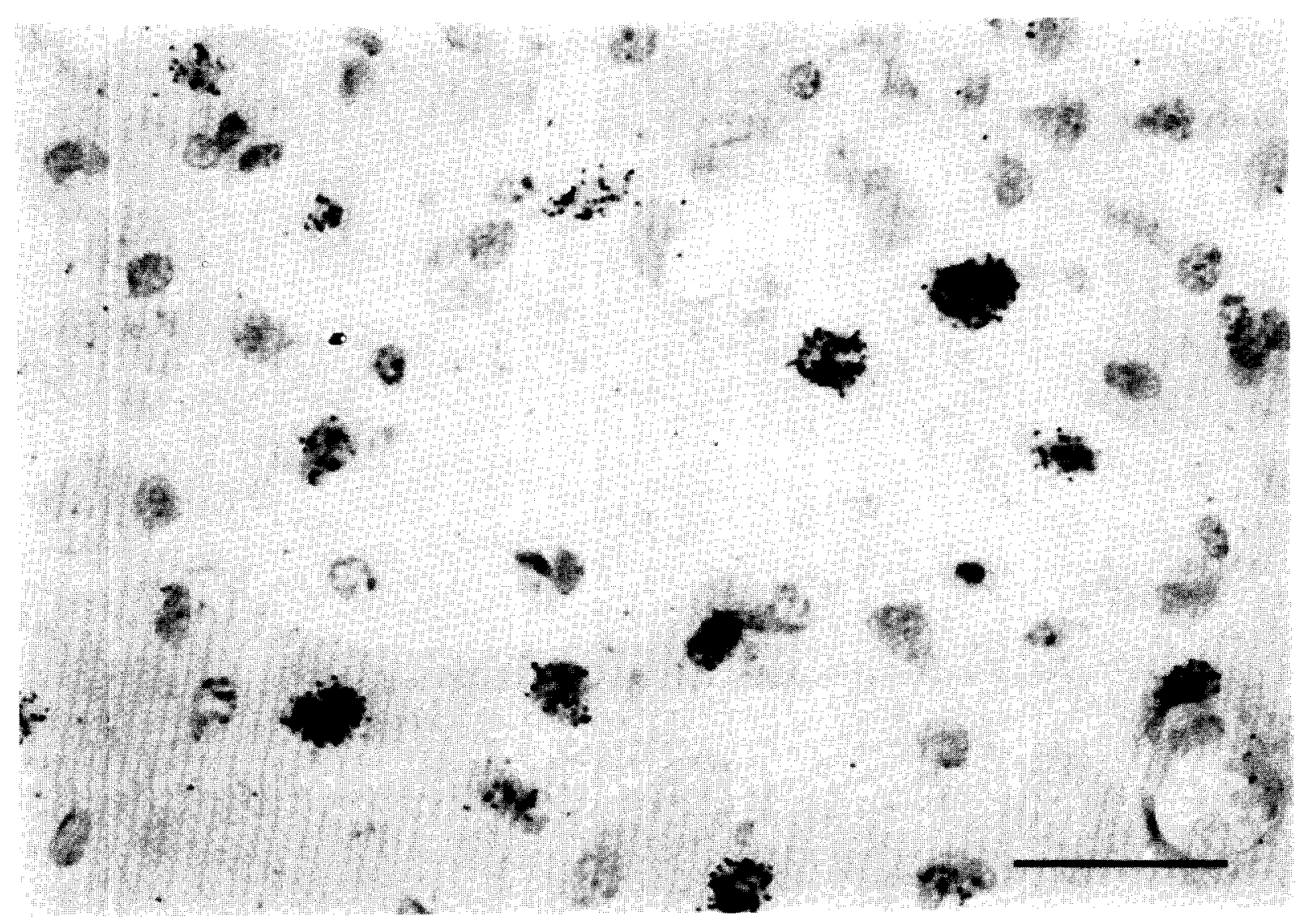

Fig. 4. Autoradiograph of an infarct at 3 days after 45 min occlusion. A high percentage of labeled cells is present at this time. Hemitoxylin/eosin. Bar $=50 \mu \mathrm{m}$. 
duced increase in metabolic rates of neurons and astrocytes ${ }^{23}$, favorably altering blood flow ${ }^{4}$ or stabilizing cell membranes ${ }^{8}$. Yoshida et al.40, comparing halothane vs pentobarbital anesthesia with respect to survival of gerbils following $30 \mathrm{~min}$ of bilateral common carotid artery occlusion, found a significantly higher survival rate (57\% compared to $2 \%$ at 1 week) when pentobarbital was used. We have used pentobarbital not only as an anesthetic during the carotid occlusion, but also as an anticonvulsant, to rescue the gerbils that developed severe generalized seizures following $45 \mathrm{~min}$ bilateral carotid occlusion. We found that without this treatment, such animals always died within $24 \mathrm{~h}$; with it, they survived.

The consistent occurrence of infarction in the caudal thalamus/midbrain region is apparently due to the fact that in the gerbil this area is the border zone between carotid and basilar arterial supplies 25,30 . Blood flow during bilateral carotid occlusion has been measured: while it is essentially zero in cortex, hippocampus and striatum, and unaltered in cerebellum and pons-medulla, it is reduced to $30-40 \%$ in the midbrain/diencephalon ${ }^{3,29}$. Thus, during bilateral carotid occlusion in the gerbil, this area is exposed to partial, rather than total, ischemia. The importance of suboptimal metabolic activity in ischemic tissue, specifically tissue lactic acidosis, as a contributing factor to irreversible tissue damage has been shown ${ }^{16,32}$. Consistent with this data is that of Choki et al. ${ }^{7}$ who demonstrated autoradiographically that glucose uptake was greater than normal in this border zone, and lower in ischemic areas. This increase occurred unilaterally in some animals; this finding and the occurrence of unilateral infarction in the present study are most likely due to variable posterior communicating arteries.

The stimuli which lead a particular cell, such as an astrocyte or endothelial cell, to leave its normally quiescent state and divide are largely unknown. Several substances, however, have been recently identified which may have a role in post-infarction cell proliferation. Platelet-derived growth factor from serum has been shown to be a potent growth factor for glia, fibroblasts and smooth muscle cells ${ }^{14,35}$ and may dif-

\section{REFERENCES}

1 Adrian, E.K. and Williams, M.G., Cell proliferation in in- fuse into an infarcted area following disruption of the blood-brain barrier. A macrophage derived growth factor which stimulates endothelial cells has been isolated 11,41 , and this factor may become available upon arrival of monocytes and their conversion into phagocytic macrophages. Finally, neural tissue itself is a source of a variety of cell proliferative factors, including fibroblast growth factor ${ }^{13}$, endothelial cell growth factor ${ }^{28}$ and brain and retinal derived growth factors 2,12 . Possibly, such factors are released into the neuropil from ischemic, degenerating neurons and stimulate proliferation of non-neuronal cells. In the present model, cell proliferation occurs in a discrete area of the brain and during a limited time after ischemia. It should, therefore, be useful in studying growth factors present in brain. For example, would soluble extracts prepared from infarct areas dissected from brains at 3-6 days postischemia have greater growth stimulatory activity in a cultured cell assay than those from 10 days postischemia?

The relevance of postinfarction cellular proliferation to the clinical outcome of a patient who has had a stroke is not immediately clear. For instance, while the glial scar that forms in brain injuries undoubtedly provides structural support for the necrotic area, it might also constitute a barrier to the re-establishment of neuronal circuitry. An additional question is whether dividing microvessel cells or the passage of leukocytes through microvessel walls might allow leakage of serum into surrounding brain tissue, causing subsequent edema. The present model should lend itself to studying the neuropathological consequences of manipulating cell proliferation, such as by administering antimitotic agents, as well as the testing of drug regimes aimed at preventing infarction.

\section{ACKNOWLEDGEMENTS}

This research was funded in part by a grant from the March of Dimes Birth Defects Foundation. M.d.B. was supported by a NRSA traineeship awarded to the Department of Neurology, University of Michigan.

jured spinal cord. An electron microscopic study, J. Comp. Neurol., 151 (1973) 1-24.

2 Barritault, D., Plouet, J., Courty, J. and Courtois, Y., Pu- 
rification, characterization, and biological properties of the eye-derived growth factor from retina: analogies with brain-derived growth factor, J. Neurosci. Res., 8 (1982) $477-490$.

3 Betz, A.L., Iannotti, F. and Hoff, J.T., Ischemia reduces blood-to-brain glucose transport in the gerbil, J. Cereb. Blood Flow Metab., 3 (1983) 200-206.

4 Branston, N.M., Hope, T. and Symon, L., Barbiturates in focal ischemia of primate cortex: effects on blood flow distribution, evoked potentials, and extracellular potassium, Stroke, 10 (1979) 647-653.

5 Cancilla, P.A. and DeBault, L.E., Freeze-injury and repair of cerebral microvessels, Adv. Exp. Med. Biol., 131 (1980) $257-269$.

6 Cavanagh, J.B., The proliferation of astrocytes around a needle wound in the rat brain, J. Anat. (London), 106 (1970) 471-487.

7 Choki, J., Greenberg, J. and Reivich, M., Regional cerebral glucose metabolism during and after bilateral cerebral ischemia in the gerbil, Stroke, 14 (1983) 568-574.

8 Demopoulous, H.B., Flamm, E.S. and Seligman, M.L., Antioxidant effects of barbiturates in model membranes undergoing free radical damage, Acta Neurol. Scand., Suppl. 64, 56 (1977) 7.10-7.11.

9 Dodson, R.F., Chu, L.W.-F., Welch, K.M.A. and Achar, V.S., Acute tissue response to cerebral ischemia in the gerbil. An ultrastructural study, J. Neurol. Sci., 33 (1977) $161-170$

10 Garcia, J.H. and Kamijyo, Y., Cerebral infarction. Evolution of histopathological changes after occlusion of a middle cerebral artery in primates, J. Neuropath. Exp. Neurol., 33 (1974) 408-421.

11 Gimbrone, M.A., Martin, B.M., Baldwin, W.M., Unanue, E.R. and Cotran, R.M., Stimulation of vascular cell growth by macrophage products. In H.L. Nossel and H.J. Vogel (Eds.), Pathobiology of the Endothelial Cell, Academic Press, New York, 1982, pp. 3-16.

12 Glaser, B.M., D'Amore, P.A., Michels, R.G., Patz, A. and Fenselau, A., Demonstration of vasoproliferative activity from mammalian retina, J. Cell Biol., 84 (1980) 298-304.

13 Gospodarowicz, D., Purification of a fibroblast growth factor from bovine pituitary, J. Biol. Chem., 250 (1975) 2515-2520

14 Heldin, C.H., Westermark, B. and Wasteson, A., Specific receptors for platelet-derived growth factor on cells derived from connective tissue and glia, Proc. Natl. Acad. Sci. U.S.A.. 78 (1981) 3664-3668.

15 Hoff, J.T., Smith, A.L., Hankinson, H.L. and Nielsen, S.L., Barbiturate protection from cerebral infarction in primates, Stroke, 6 (1975) 28-33.

16 Hossmann, K.-A. and Zimmerman, V., Resuscitation of brain after one hour of complete ischemia. I. Physiological and morphological observations, Brain Research, 81 (1974) $59-74$

17 Ito. U., Go, K.G., Walker, J.T., Spatz, M. and Klatzo, I., Experimental cerebral ischemia in Mongolian gerbils. III. Behavior of the blood-brain barrier, Acta Neuropath. (Berlin), 34 (1976) 1-6.

18 Ito, U., Spatz, M., Walker, J.T. and Klatzo, I., Experimental cerebral ischemia in Mongolian gerbils. I. Light microscopic observations, Acta Neuropath. (Berlin), 32 (1975) 209-223.

19 Jarrott, D.M. and Domer, E.R., A gerbil model of cerebral ischemia suitable for drug evaluation, Stroke, 11 (1980) 203-209.

$20 \mathrm{Kahn}, \mathrm{K}$., The natural course of experimental infarction in the gerbil, Neurology, 22 (1972) 510-515.

21 Kirino, T., Delayed neuronal death in the gerbil hippocampus following ischemia, Brain Research, 239 (1982) 57-69.

22 Kobayashi, M., Lust, W.D. and Passonneau, J.V., Concentration of energy metabolites and cyclic nucleotides during and after bilateral ischemia in the gerbil cerebral cortex, J. Neurochem., 29 (1977) 53-59.

23 Kofke, W.A., Nemoto, E.M., Hossmann, K.A., Taylor, F., Kessler, D.D. and Stezoski, S.W., Brain blood flow and metabolism after global ischemia and post-insult thiopental therapy in monkeys, Stroke, 10 (1979) 554-560.

24 Latov, N., Nilaver, G., Zimmerman, E.A., Johnson, W.G., Silverman, A., Defendini, R. and Cote, L., Fibrillary astrocytes proliferate in response to brain injury. A study combining immunoperoxidase technique for glial fibrillary acidic protein and radioautography of tritiated thymidine, Dev. Biol., 72 (1979) 381-384.

25 Levy, D.E. and Brierley, J.B., Communications between vertebrobasilar and carotid arterial circulations in the gerbil, Exp. Neurol., 45 (1974) 503-508.

26 Levy, D.E. and Brierley, J.B., Delayed pentobarbital administration limits ischemic brain damage in gerbils, Ann. Neurol., 5 (1979) 59-64.

27 Levy, D.E., Brierley, J.B. and Plum, F., Ischemic brain damage in the gerbil in the absence of 'no-reflow', J. Neurol. Neurosurg. Psychiat., 38 (1975) 1197-1205

28 Maciag, T., Hoover, G.A. and Weinstein, R., High and low molecular weight forms of endothelial cell growth factor, J. Biol. Chem., 257 (1982) 5333-5336.

29 Matsumoto, M., Kimura, K., Fumisawa, A., Matsuyama, T., Fukunaga, R., Yoneda, S., Wada, H. and Abe, H., Differential effect of cerebral ischemia on monoamine content of discrete brain regions of the Mongolian gerbil (Meriones unguiculatus), J. Neurochem., 42 (1984) 647-651.

30 Matsuyama, T., Matsumoto, M., Fujisawa, A., Handa, N., Tanaka, K., Yoneda, S., Kimura, K. and Abe, H., Why are infant gerbils more resistant than adults to cerebral infarction after carotid ligation?, J. Cereb. Blood Flow Metab., 3 (1983) 381-385

31 Murabe, Y., Ibata, Y. and Sano, Y., Morphological studies on neuroglia. II. Response of glial cells to kainic acid-induced lesions, Cell Tiss. Res., 216 (1981) 569-580.

32 Nordstrom, C.H., Rehncrona, S. and Siesjo, B.K., Restitution of cerebral energy state, as well as glycolytic metabolites, citric acid cycle intermediates and associated amino acids after 30 minutes of complete ischemia in rats anesthetized with nitrous oxide or phenobarbital, $J$. Neurochem., 30 (1978) 479-486.

33 Persson, L., Cellular reactions to small cerebral stab wounds in the rat frontal lobe. An ultrastructural study, Virchows Arch. Cell. Pathol., 22 (1976) 21-37.

34 Robins, M. and Baum, H.M., The national survey of stroke. Incidence, Stroke, Suppl. 1, 12 (1981) I-45-I-55.

35 Ross, R., Glomset, J., Kariya, B. and Harker, L., A platelet-dependent serum factor that stimulates the proliferation of arterial smooth muscle cells in vitro, Proc. Natl. Acad. Sci. U.S.A., 71 (1974) 1207-1210.

36 Sacco, R.L., Wolf, P.A., Kannel, W.B. and McNamara, P.M., Survival and recurrence following stroke: the Framingham study, Stroke, 13 (1982) 290-295.

37 Slager, U.T., Basic Neuropathology, Williams and Wilkins, 
Baltimore, MD, 1970, 50 pp.

38 Smith, A.L., Hoff, J.T., Nielsen, S.L. and Larson, C.P., Barbiturate protection in acute focal cerebral ischemia. Stroke, 5 (1974) 1-7.

39 Westergaard, E., Go, G., Klatzo, I. and Spatz, M. Increased permeability of cerebral vessels to horseradish peroxidase induced by ischemia in Mongolian gerbils. Acta Neuropath. (Berlin), 35 (1976) 307-325.
40 Yoshida, S., Inoh, S., Asano, 1., Sano, K.. Shimasaki ti. and Ueta, N. Brain free fatty acids. edema, and mortality in gerbils subjected to transient bilateral ischemia, and ef fect of barbiturate anesthesia. I. Neurochom. fit $[198,3)$ $1278-1286$

41 Ziats. N.P. and Robertson. A.L.. Effects of peripheral blood monocytes on human vascular cell proliferation. Ath erosclerosis, 38 (1981) 401-410 